\title{
The Taxation of Environmental Pollution: A Model for Tax Revenue-Environmental Quality Tradeoffs
}

\author{
Hung-Ming Peter $\mathrm{Wu}^{1} \&$ Keith D. Willett ${ }^{2}$ \\ ${ }^{1}$ Assistant Professor, Department of Public Finance and Taxation, Aletheia University, New Taipei City, Taiwan \\ (R.O.C.) \\ 2 Professor, Department of Economics and Legal Studies in Business, Spears School of Business, Oklahoma State \\ University, Stillwater, Oklahoma, USA \\ Correspondence: Hung-Ming Peter Wu, Assistant Professor, Department of Public Finance and Taxation, Aletheia \\ University, No.32, Zhenli St., Danshui Dist., New Taipei City 25103, Taiwan (R.O.C.). Tel: 886-2-2626-2737 ex. \\ 8603 .
}

Received: December 8, 2016

doi:10.5430/ijfr.v8n1p65
Accepted: December 21, 2016

Online Published: December 28, 2016

URL: http://dx.doi.org/10.5430/ijfr.v8n1p65

\begin{abstract}
The paper analyzes the Willamette River in Oregon. Here a model (combining the least-cost model and the constraint method of multi-objective programming) is used to determine the appropriate tax rate on environmental externalities, incorporating both revenue and environmental quality objectives. The study finds the following. (1) By using the optimal tax rate, the appropriate tax revenue is determined. (2) The efficient solution set (including tax revenue and water quality considerations) is found by using differing optimal tax rates. (3) The optimal point (solution) in the efficient solution set is chosen by the geometrical argument approach and trade-off analysis approach.
\end{abstract}

Keywords: water quality control, environmental tax, least cost model, constraint method of multi-objective programming

\section{Introduction}

Historically, economists have advocated environmental policies that are based on economic incentives. These policies can take many different forms, but perhaps the most widely discussed variant is based on the use of taxes (Baumol and Oates, 1988). In contrast, there seemed to be very little enthusiasm and support in the policy-making arena for the use of taxes as the basic foundation for an environmental policy.

The perspective on the use of taxes in an environmental policy has begun to change over the years. One important reason is based on the belief that environmental taxes, or "green taxes," offer a "double dividend." First, as economists have long argued, appropriately defined taxes can efficiently restrain the levels of polluting activities. Second, these taxes also generate revenues, thus allowing a reduction of rates on other forms of taxation throughout an economy that distort the functioning of the economy. The latter point means there will be an increase in the efficiency of the overall tax system. The efficiency aspects of the double dividend argument for "green taxes" have been extensively reviewed and discussed by Oates $(1993,1995)$. These issues are beyond the scope of this paper. Instead, this paper focuses more directly on the role of tax revenue objectives and environmental quality objectives in the taxation of pollution.

Burke (1997) and Barde and Smith (1997) present a selective country-by-country review of environmental policies that include "green taxes." Burke (1997) argues that European countries seem to have taken the lead in implementing environmental taxes through the late 1990s. In some cases, these taxes were designed to provide economic incentives (i.e., reduce emissions in order to comply with environmental objectives). In other situations, environmental taxes were designed to provide resources to finance specific pollution-abatement programs. Barde and Smith (1997) note, for example, that water-effluent charges played an important role in financing pollution-control facilities in France. Environmental taxes were also levied in some situations to cover the costs of regulating emissions. In yet other cases, environmental taxes were used as incentives to move toward the achievement of environmental quality objectives. Examples here include a $\mathrm{CO}_{2}$ tax in Sweden and Norway (Burke, 1997). Metcalf (2009) discusses the prospect of using a carbon tax to reduce greenhouse gas emissions in the U.S. 
The task of determining environmental tax rates quickly becomes a complicated issue in a realistic policy setting where the basic problem is one of trying to use a single instrument to regulate pollution and raise revenues. These appear to be conflicting objectives, which means that there are tradeoffs in the sense that sacrificing the requirements of one goal will produce greater returns on the other. This clearly requires a decision-making protocol that addresses the tradeoffs between environmental quality objectives and tax revenue objectives. Such a protocol must recognize that decision makers are faced with different objectives that may be of equal or differing importance. In some situations, the goals may not be commensurate; they may not be directly compared or combined. The goals may also conflict, which means there are tradeoffs in the sense that sacrificing the requirements of one goal will produce greater returns on the others.

The decision-making problem outlined in the previous paragraphs can easily be couched in terms of a multiple-objective or multi-criteria decision problem. A common practice is to solve these problems with a multi-objective programming (MOP) or vector optimization technique (Romero and Rehman, 2003; Ballestero and Romero, 1998). This technique is designed to seek simultaneous optimization of several objectives subject to a common constraint set that is usually linear. An optimal solution cannot be defined for several simultaneous objectives, so a solution strategy must be designed to obtain the set containing efficient solutions instead of locating a single optimal solution. The set of efficient solutions is said to be nondominated or Pareto efficient. Cohon and Marks (1973) applied multi-objective theory and the constraint method to a water resource development and allocation problem. Detailed descriptions of multi-objective optimization and the generation of Pareto optimum can be found in sources such as Cohon (1978), Cohon and Marks (1973), Romero and Rehman (2003), Ballestero and Romero (1998) and Deb (2014).

Multi-objective or multi-criteria decision-making problems can also be formulated and solved as either "compromise programming" or "goal programming" problems. Problem formulation and solution strategies are given extensive coverage in Romero and Rehman (2003). (Also see Ballestero and Romero, 1998) The range of applications of weighted goal programming to the analysis of tradeoffs in public policy problems include Barnett et al. (1982) and Spronk and Veeneklass (1983) as well as Wheeler and Russell (1977).

A tax is the same as an effluent charge. After solving a least cost model, we can use the tax to implement a least cost solution. The tax rate can be set equal to marginal treatment cost. In order to implement the above approach, we need to know the set of cost functions (total cost or marginal cost) of all dischargers. Revelle, Loucks, and Lynn (1968) provide an example of a modeling system that contains such information. It is possible in theory to implement a least-cost solution using effluent charges after a least-cost model is solved. The shortcoming of this particular protocol is that the abatement cost functions for all dischargers are needed to calculate the vector of individual unit charges required to achieve the required set of waste reduction levels (Brill, 1997).

The purpose of this paper is to develop a modeling structure (combining a least-cost model and the constraint method of multi-objective programming) that is used to determine the appropriate tax rate on environmental externalities, incorporating both revenue and environmental quality objectives. The uniqueness of this paper lies with the manner in which the multiple objectives of tax revenues and environmental quality are portrayed. The tax rate used in this paper on emissions is determined by solving a least-cost model as suggested by Brill (1997). Roskamp (1972) developed a mathematical programming-based policy decision model approach to optimal budgets. Chrisman et al. (1989) provided another example of a multi-objective programming model been developed for public sector tax planning. The tax rates are assumed to be known and fixed by Chrisman et al. (1989).

A related objective of this paper is to show a model (combining the least-cost model and the constraint method of multi-objective programming model) that can be used to determine the most efficient tradeoffs between a tax rate on environmental externalities that incorporates both revenue and environmental quality objectives. The discussions in this paper thus focus on the detailed development of the combined model structure (the least-cost model and the constraint method of multi-objective programming model) and finding the efficient solution set for a decision maker.

The organizational structure of this paper is as follows. First, a short discussion is presented of how the tax rate could be determined given the two different objectives. Second, a simplified version of a water quality model is presented and then extended to a constraint method of multi-objective programming model. This section will also address some of the issues relevant to the determination of the constraint from the least-cost model for the objective function. Third, this section presents an expanded version of a model that will be implemented along with potential data sources. Finally, solutions and results are presented. 


\section{Modeling Structure}

This section provides some relevant information that is concerned with the modeling structure. In the first subsection, the key characteristics of tax revenue are discussed, including the selection of a tax rate and the tax base. The second subsection presents the water quality model and cost-minimization problem. The third subsection presents the multiple-objective model that is based on the constraint method. Finally, the multi-objective programming model is applied to the water quality management problem.

\subsection{Tax Revenue}

The first important concern is the tax base. It is an accepted proposition that taxes on externalities should be placed directly on the activity that generates the external cost. Thus, the tax should be levied on emissions (i.e., the tax base is emissions). (For example, see Baumol and Oates [1988] or Tietenberg [1985])

Recall from earlier discussions that two different objectives were identified for setting the tax rate on emissions. Consider first the problem of setting the tax rate to achieve a target level of revenues. Clearly, there is a wide range of issues pertaining to how the target level of revenues could be determined. For example, suppose the objective is to place the pollution tax revenues into a fund designed to fund research and development activities for new pollution abatement technology. If the target level for such a fund is known and there is a reliable estimate of the tax base, it is a relatively simple task to calculate the average tax rate that should be assessed. At best, the process of identifying the target level for tax revenues and the corresponding tax rate is an ad hoc procedure.

The second criterion is concerned with environmental management objectives. Assume in this case that the tax rate is determined on the basis of the "standards and charges" approach advocated by Baumol and Oates (1988). This proposition states that a tax rate set at a level that achieves the desired reduction in total emission of pollutants satisfies the necessary conditions for the minimization of the program's total costs to society. (A detailed account of the tax rate derivation is not presented in these discussions. The reader is referred to Baumol and Oates [1988].)

The major shortcoming of the methods outlined above lies with their failure to directly address the tradeoffs between the revenue objectives and environmental objectives in the selection of a tax rate. The tradeoffs in this research are ultimately addressed within the context of the constraint method of a multi-objective programming framework. The statement of the constraint method of the multi-objective programming framework is developed in a series of stages in the following subsections.

\subsection{Water Quality Model}

Consider first the nature of the pollutant to be addressed in this study. The relevant type of pollutant is called a "non-uniformly mixed fund pollutant" (Tietenberg, 1985). The distinguishing feature of this type of pollutant is that the environment has some amount of assimilative capacity for them. (That is, the environment can absorb them to some extent.) If the assimilative capacity is high enough relative to the rate of release to the environment, they are not likely to accumulate.

A type of water pollutant is called "biodegradable" because it degrades or breaks into its component parts within the water. An easy way to measure and state the concentration of biodegradable or organic wastes that reveals the concentration of organics as well as the amount of oxygen that all organic wastes, acting together, will eventually remove from the water is called biochemical oxygen demand (BOD). BOD is the amount of oxygen, determined by testing, that would be consumed if all the organics in one liter of polluted water were oxidized in the presence of air by bacteria and protozoa. This is reported in number of milligrams of oxygen per liter. The discussions in this paper are focused on BOD and its fixed point sources.

The pollutant BOD is a measure of organic waste load that indicates the amount of oxygen drawn up (demanded) in the process of waste decomposition. The rate at which a given quantity and type of organic waste exerts oxygen demand is a function of a set of factors, including chemical characteristics, the temperature of the receiving water, and the type of waste. The rate at which BOD is exerted combined with the rate at which oxygen is restored determines the dissolved oxygen level. The critical measure of environmental quality is dissolved oxygen (DO).

A set of mathematical relationships summarizing these conditions can be developed as follows. A river that is modeled is divided into sections called "reaches." A new reach is defined when one of the following occurs: the flow of the river is altered by effluent entering the river, incremental flow entering the river (groundwater or tributary flow), or the flow in the main channel is augmented or diverted or when a change occurs in parameters describing the river's response to effluent. The critical point for measuring environmental quality in a reach is where DO is at its lowest level. This is called the "sag point" and occurs at the end of the reach. This sag point is referred to as the 
"monitoring point" for environmental quality in the remaining discussions. It is also assumed that each fixed point discharger in a reach can have an impact on the level of water quality in the reaches that are located downstream.

These relationships can be formally presented as follows. Let the index $i(i=1, \ldots, I)$ denote a fixed-point discharge source, $k(k=1, \ldots, K)$ the reach number where the fixed-point discharger is located, and $j(j=1, \ldots, J)$ the reach number where water quality is being measured. In addition, define the following notation.

$D_{j} \equiv$ dissolved oxygen deficit at monitoring point $j(\mathrm{mg} / \mathrm{l})$,

$B_{j} \equiv$ background dissolved oxygen deficit at point $j(\mathrm{mg} / \mathrm{l})$,

$E_{i k} \equiv$ BOD emissions from source $i$ in reach $k$,

$a_{k i j} \equiv$ transfer coefficient to translate BOD emissions from source $i$ in reach $k$ to their effect on the dissolved oxygen deficit at the receptor point in each $j$,

$S_{j} \equiv$ dissolved oxygen concentration at location $j(\mathrm{mg} / \mathrm{l})$,

$X_{i k} \equiv$ percent of BOD removed by source $i$ in reach $k$,

$T_{j} \equiv$ dissolved oxygen saturation at location $j(\mathrm{mg} / \mathrm{l})$.

The relationship between BOD releases from the fixed-point sources in a reach and the level of water quality at each impacted monitoring point downstream is summarized by the following relationship.

$$
\begin{gathered}
D_{j}=B_{j}+\sum_{k=1}^{J} \sum_{i=1}^{I} a_{k i j} E_{k i} \\
(j=1, \ldots, J) .
\end{gathered}
$$

An example of the situation presented by equation (1) is shown in Figure 1. There are several important points of which to be aware regarding equation (1). First, discharge points downstream from each monitoring point have no impact at the point in question. Second, it is not possible to reduce the dissolved oxygen deficit level $D_{j}$ to zero unless the BOD discharge levels from all point sources along with the background levels of BOD are all equal to zero. Third, the transfer coefficients are generally smaller the further upstream a point source is from the monitoring point. Finally, the transfer coefficient $a_{k i j}$ is assumed to be constant in the remaining discussion and indicates the amount that the concentration level of dissolved oxygen will change at the receptor point $j$ as a result of a one-unit change in BOD release at point-source location $i$ in reach $k$. A more complex and realistic presentation of the water quality modeling system is presented in a later section.

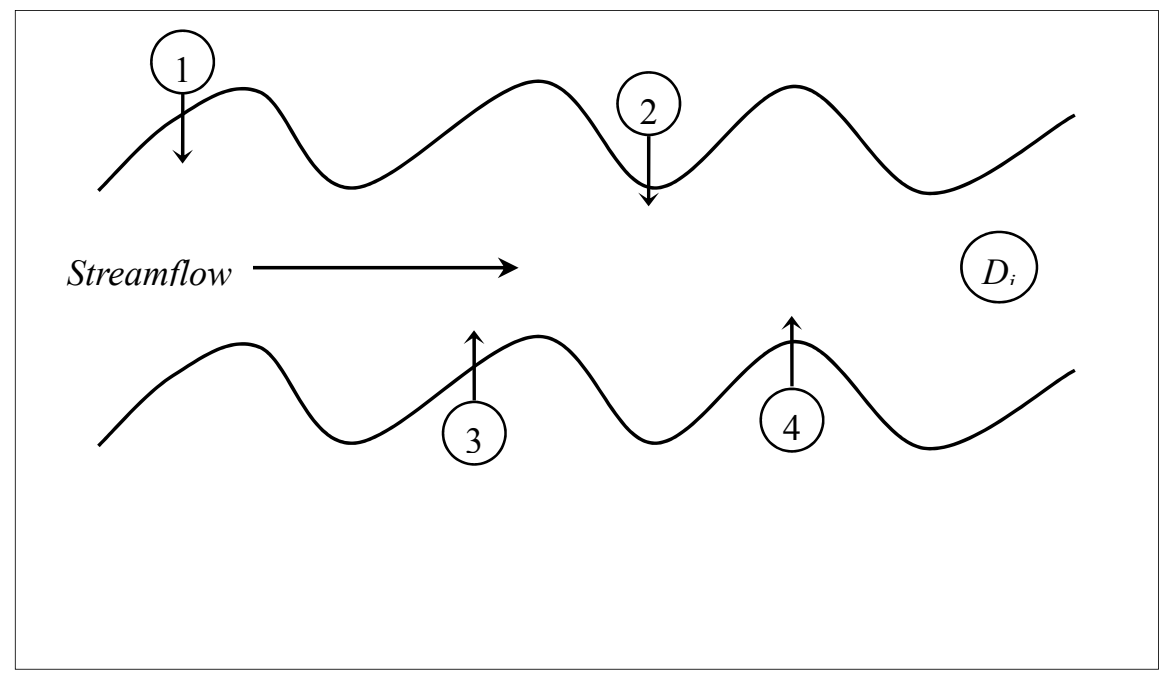

Figure 1. Effect of location on local pollution concentration 
Water quality policy is normally stated in terms of ambient standards and measured in units of dissolved oxygen concentration rather than a dissolved oxygen deficit. The relationship between the dissolved oxygen level at monitoring location $j$ and the dissolved oxygen concentration level at this location is stated as:

$$
\begin{gathered}
S_{j}=T_{j}-D_{j} \\
(j=1, \ldots, J) .
\end{gathered}
$$

Equation (2) states that the dissolved oxygen concentration at location $j$ is equal to the dissolved oxygen saturation at location $j$ minus the dissolved oxygen deficit at point $j$, which is also a monitoring point. In summary, equations (1) and (2) provide a representation of the physical conditions of each section of the river and the corresponding impacts of emissions to that section of the river. The information for these equations is often derived from an environmental quality simulation model.

The next task is to develop a cost-minimizing model. First, several modifications must be made to equations (1) and (2) to reflect the presence of pollution abatement activities as well as the water quality objective. Recall that the standard or water quality target is set in terms of DO at the receptor point in each reach. Let the minimum DO level be denoted as $\bar{S}_{j}$. Then equation (2) is restated as:

$$
\begin{gathered}
T_{j}-D_{j} \geq \bar{S}_{j} \\
(j=1, \ldots, J) .
\end{gathered}
$$

But if $T_{j}$ is viewed as fixed and given, then equation (3) can be restated as:

$$
\begin{gathered}
D_{j} \leq T_{j}-\bar{S}_{j} \\
\quad(j=1, \ldots, J) .
\end{gathered}
$$

Equation (1) must also be modified to represent the percentage of BOD removal in each reach, which is the decision variable for each pollution source. If $X_{i k}$ represents the percentage of BOD removed by source $i$ in reach $k$, then (1$\left.X_{i k}\right) E_{i k}$ represents the amount of BOD remaining. Taking this into account in equation (1) leads to the following statement.

$$
\begin{gathered}
B_{j}+\sum_{k=1}^{j} \sum_{i=1}^{I} a_{k i j}\left(1-X_{i k}\right) E_{i k}=D_{j} \\
(j=1, \ldots, J)
\end{gathered}
$$

The next item that must be specified is the cost of pollution abatement. This is initially represented in a very general manner as $C_{i k}\left(X_{i k}\right)$. Furthermore, it is assumed that:

$$
\frac{d C_{i k}}{d X_{i k}}\left(X_{i k}\right)>0 \text { and } \frac{d^{2} C_{i k}}{d X_{i k}^{2}}\left(X_{i k}\right)>0 .
$$

Graphically, this means that the pollution control cost function is as shown in Figure 2. This general form is consistent with most empirically observed situations. Notice that as the percentage of BOD removal increases, the marginal cost of BOD removal increases significantly. How this relationship actually appears depends on each particular situation. 


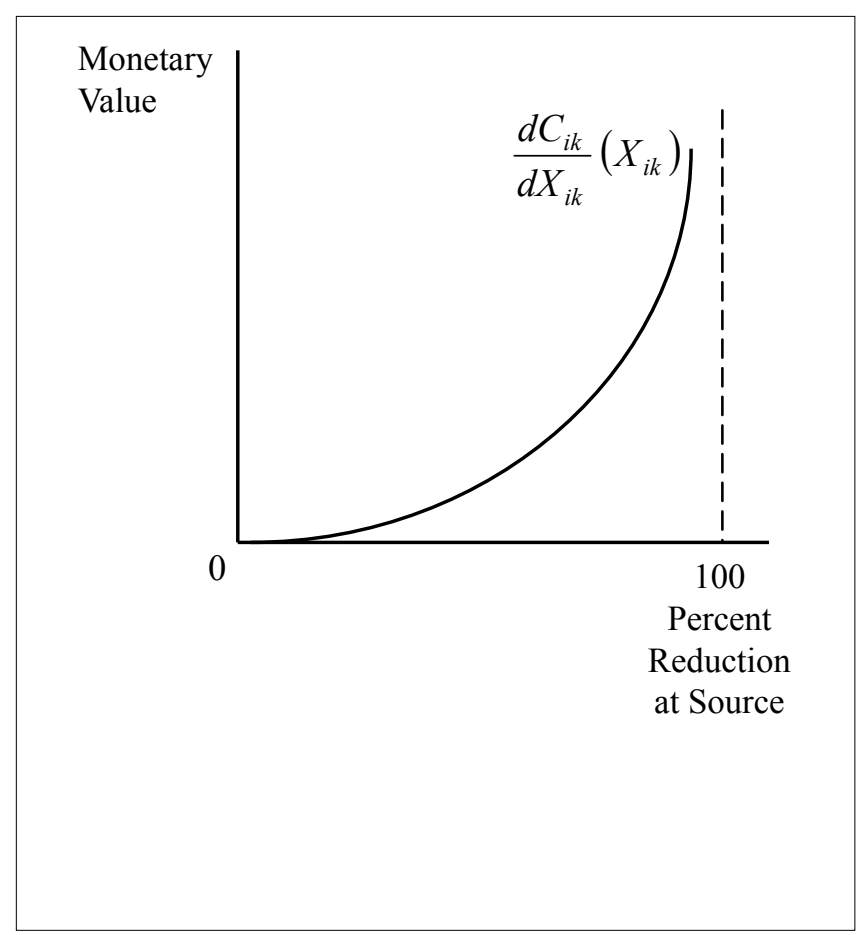

Figure 2. Pollution control cost function for source $i k$

The perspective for the environmental policy makers is assumed to cover all fixed-point discharges over a well-defined number of reaches along a river. Thus environmental policy makers are concerned with $I$ fixed-point discharges over $J$ reaches along the river. The environmental policy maker's cost-minimization problem is stated as

$$
\min _{X_{i k}} \sum_{k=1}^{J} \sum_{i=1}^{I} C_{i k}\left(X_{i k}\right)
$$

subject to

$$
\begin{gathered}
\sum_{k=1}^{J} \sum_{i=1}^{I} a_{k i j}\left(1-X_{i k}\right) E_{i k} \leq \bar{R}_{j} \\
(j=1, \ldots, J)
\end{gathered}
$$

where $\bar{R}_{j}=T_{j}-\bar{S}_{j}-B_{j}$ for $j=1, \ldots, J$. Recall that $T_{j}$ and $B_{j}$ are constants while $\bar{S}_{j}$ is the ambient water quality objective.

The solution to the cost minimization model given by equations (6) and (7) represents the environmental quality objective problem perspective. This solution also provides the theoretical foundation for the "standards and charges" approach advocated by Baumol and Oates (1988). This proposition states that a tax rate set at a level that achieves the desired reduction in the total emissions of pollutants satisfies the necessary conditions for the cost minimization problem. Moreover, this tax rate is equal to the shadow price for constraint (7).

\subsection{Multi-Objective Mathematical Model by Using Constraint Method}

The general statement for a multi-objective problem with $p$ objectives takes the following general form (Cohon, 1978). 


$$
\begin{gathered}
\operatorname{Max} Z\left(X_{1}, X_{2}, \ldots, X_{n}\right)= \\
{\left[Z_{1}\left(X_{1}, X_{2}, \ldots, X_{n}\right), Z_{2}\left(X_{1}, X_{2}, \ldots, X n\right),\right.} \\
\left.Z_{n}\left(X_{1}, X_{2}, \ldots, X_{n}\right), Z_{p}\left(X_{1}, X_{2}, \ldots, X_{n}\right)\right] \\
\text { St. }\left(X_{1}, X_{2}, \ldots, X_{n}\right) \in F_{d}
\end{gathered}
$$

where $Z_{1}, Z_{2}, \ldots, Z_{p}$ are objective functions; $X_{1}, X_{2}, \ldots, X_{n}$ are decision variables; and $F_{d}$ is the feasible resource.

The general statement for the constraint method that can be used to solve a multi-objective programming problem takes the following form.

$$
\begin{gathered}
\text { Maximize } Z_{h}\left(X_{1}, X_{2}, \ldots, X_{n}\right) \\
\text { St. }\left(X_{1}, X_{2}, \ldots, X_{n}\right) \in F_{d} \\
Z_{k}\left(X_{1}, X_{2}, \ldots, X_{n}\right) \geq L_{k} \\
K=1,2, \ldots, h-1, h+1, \ldots, p
\end{gathered}
$$

where $Z_{1}, Z_{2}, \ldots, Z_{p}$ are objective functions; $X_{1}, X_{2}, \ldots, X_{n}$ are decision variables; $F_{d}$ is the feasible resource; $L_{k}$ is the lower bond of $K$ th objective; and $h$ th objective is arbitrarily chosen for maximization. This formulation converts the problem into a single-objective problem, allowing it to be solved using conventional methods. The optimal solutions to the multi-objective problem are a set of non-inferior solutions to the original multi-objective problem (Cohon, 1978). In order to find the non-inferior solution, two conditions must be met. First, $Z_{k} \geq L^{\prime}$, where $L^{\prime}$ is the lower bound of objective $Z_{k}$. The result will be feasible solutions. Another condition is the choice of the right side value, $L$, which should be binding.

Cohon (1978) observes that given the choice of $L_{k}$, all of the constraints on the objectives should be binding at the optimal solution for the constrained problem. If this outcome is not the case, and if there are other optimal outcomes for the constrained optimization problem, it is likely that some of these optimal solutions are inferior alternatives for the original multi-objective problem. The right side value of this constraint, $L_{k}$, is set at zero or at some predetermined value. We can increase this value incrementally until the solution becomes infeasible. A point in the non-inferior set is found by the value of the right side value.

\subsection{Multi-Objective Programming Applied in Water Quality Management}

Water quality management in a river basin can be modeled as a multi-objective programming problem. In general, water quality management in a river basin using this perspective searches for feasible alternatives to attain the following goals: (1) find a reasonable allocation of waste load for each source to discharge in a river, (2) achieve water quality standards, and (3) determine the basis for significant reductions in mass loads of pollution in a deteriorating river (Wen and Lee, 1998).

The empirical model structure and parameter value used to address the research objectives for this paper are based on the models and parameters used in Revelle, Loucks, and Lynn (1968) and Loucks, Revelle, and Lynn (1967). The models used in both of these papers are formulated as linear programming problems for managing water quality in a river basin. The research goal in both is to select the efficiencies of those treatment plants on the river modeled so as achieve a set of dissolved oxygen standards at minimum cost. The model objective function is structured in terms of the costs for the treatment plants, and the principal constraints are designed to prevent violation of dissolved oxygen standards. This paper shows two models, a least-cost model and a constraint method of multi-objective programming, which can be combined to determine the optimal tax rate on environmental externalities that incorporates both revenue and environmental quality objectives.

Since water quality objectives and tax revenue objectives may have a tradeoff relationship, we need to find the relationship and to decide the optimal solution for the tax rate. Then the objectives of water quality and tax revenue can be decided. The tax revenue is dependent on the least treatment cost, which is found by the least-cost model. Therefore, we may find the relationship between water quality and least treatment cost first. Then, by the set of least treatment costs, we can find the relationship between water quality and tax revenue. In order to find the relationship between water quality and least treatment cost, we use the constrained method model of multi-objective programming. In this approach, we use the following four steps to find the trade-off relationship between water quality and tax revenue (see Figure 3).

Step 1:

Find the least treatment cost from the least-cost model (Revelle et al. 1968). Then the least treatment cost, the 
solution in this least-cost model, is used to be the right side value of "the least cost constraint," which is in Step 2.

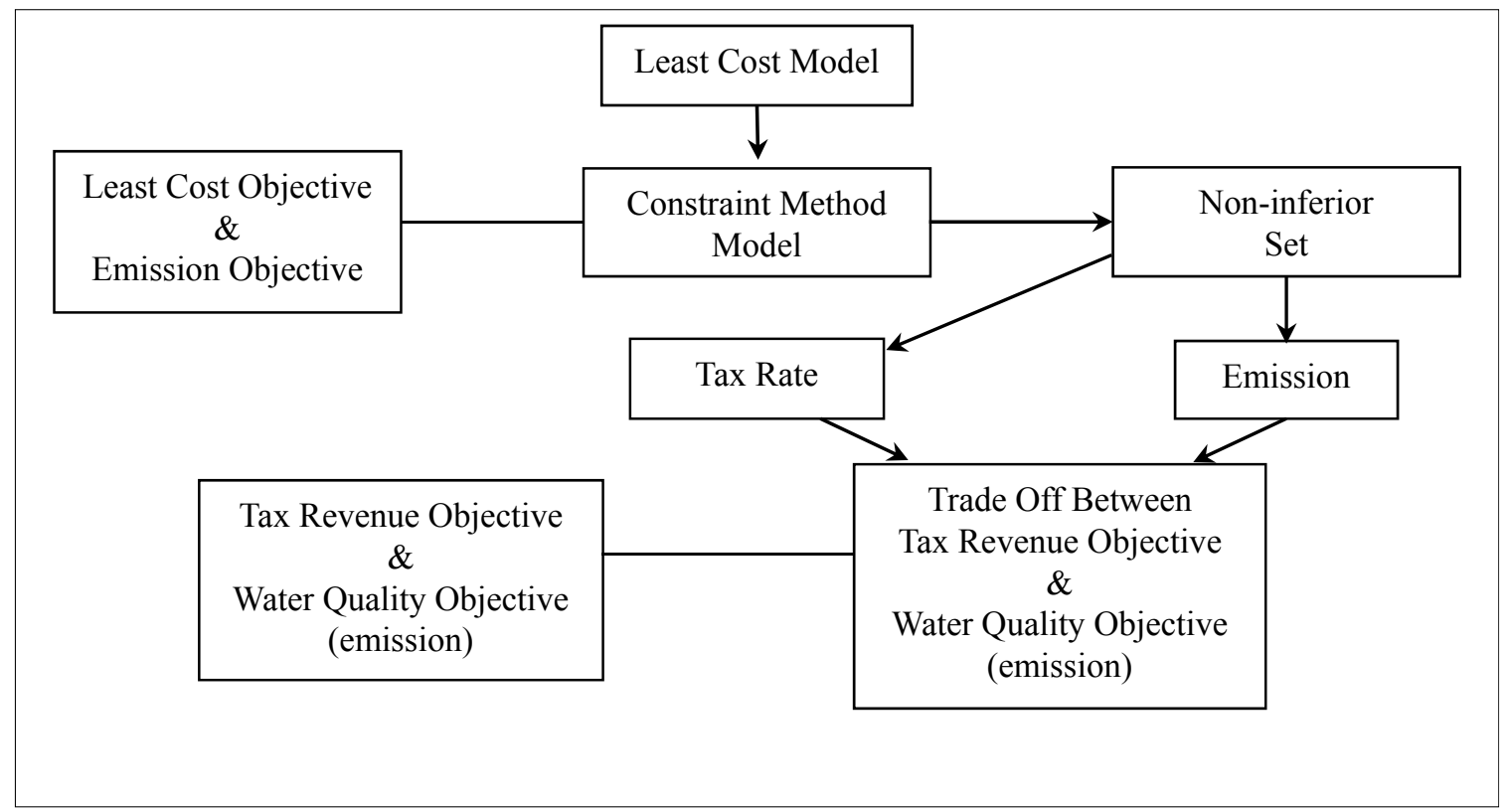

Figure 3. Procedure for finding the trade-off relationship between water quality and tax revenue

Step 2:

Set two objectives, maximizing water quality (minimizing the emission) and minimizing the least-cost objectives, in the constrained method model. Then put the least-cost objective as a constraint of this problem. The right side value of this constraint is set at the predetermined value, which is the least treatment cost found from Step 1. Now increase this value incrementally until the solution becomes infeasible. A point in the non-inferior set is found by every value of the right side value in "the least-cost constraint."

Step 3:

A value of tax revenue (tax rate multiplied by emission) is found by every point in the non-inferior set solved by Step 2. That is because we use the theory, which is to implement a least-cost solution using the tax after solving a least-cost model. The reason is explained in Section 2.1.

Step 4:

Find the relationship of tax revenue and water quality (negative emission) by drawing these points of result from above. It becomes the non-inferior set; any point in this non-inferior set is efficient.

\section{Empirical Application}

The empirical application of the concepts developed in this research is based on a version of the model used by Revelle, Loucks, and Lynn (1968). Begin by defining the following notation.

$t_{i j} \equiv$ the time of flow from the top of the $i$ th reach to the $j$ th point in the reach, days;

$m_{i} \equiv$ number of points in the $i$ th reach;

$k_{i} \equiv$ bio-oxidation constant in the $i$ th reach, days ${ }^{-1}$;

$r_{i} \equiv$ re-aeration coefficient in reach $i$, days ${ }^{-1}$;

$D_{i} \equiv$ oxygen deficit at the top of reach $i, \mathrm{mg} /$ liter;

$E_{i} \equiv$ oxygen deficit at the last point of reach $i, \mathrm{mg} /$ liter;

$T \equiv$ oxygen deficit of the waste water discharged by each plant, $\mathrm{mg} /$ liter;

$D_{A} \equiv$ allowable oxygen deficit in the system, $\mathrm{mg} / \mathrm{liter}$; 
$L_{i} \equiv$ BOD concentration at the top of reach $i, \mathrm{mg} /$ liter;

$F_{i} \equiv$ BOD concentration at the last point in reach $i, \mathrm{mg} /$ liter;

$M_{i} \equiv \mathrm{BOD}$ concentration in the effluent from treatment plant $i, \mathrm{mg} /$ liter;

$P_{i} \equiv$ BOD concentration in the waste flow entering the $i$ th treatment plant, $\mathrm{mg} / \mathrm{liter}$;

$Q \equiv$ flow rate in river, million gallons/day;

$Q_{i} \equiv$ flow rate being withdrawn by community $i$ for its water supply and being discharged as effluent from its waste treatment plant.

In addition, define the following.

$$
\begin{gathered}
f_{i j}=\left[\frac{k_{i}}{r_{i}-k_{i}}\right]\left(e^{-k_{i} t_{i j}}-e^{-r_{i} t_{i j}}\right) \\
g_{i j}=e^{-r_{i} t_{i j}} .
\end{gathered}
$$

The base case optimization model is a cost minimization model and is as follows.

$$
\min \sum_{i=1}^{n} a_{i} \varepsilon_{i}
$$

subject to

$$
\begin{gathered}
\varepsilon_{i}+\left(\frac{1}{p_{i}}\right) M_{i}=1 \\
i=1, \ldots, n \\
\left(Q-Q_{i}\right) F_{i-1}+Q_{i} M_{i}-Q L_{i}=0 \\
i=1, \ldots, n \\
-\left(Q-Q_{i}\right) E_{i-1}+Q D_{i}=T Q_{1} \\
i=1, \ldots, n \\
E_{i}-f_{i j} L_{i}-g_{i j} D_{i}=0 \\
i=1, \ldots, n-1 \\
j=m_{i} \\
F_{i}-h_{i j} L_{i}=0 \\
i=1, \ldots, n-1 \\
j=m_{i} \\
f_{i j} L_{i}+g_{i j} D_{i} \leq D_{A} \\
i=1, \ldots, n \\
j=1,2, \ldots, m_{i} \\
D_{i} \leq D_{A} \\
i=1, \ldots, n \\
\gamma_{i} \geq 0.35 \\
\gamma_{i} \leq 0.90 \\
i=1, \ldots, n .
\end{gathered}
$$


In the statement of this model, the objective function equation (13) is defined as treatment costs, while equation (14) is a definition of treatment efficiency. Equation (15) is an inventory balance equation for BOD; equation (16) is an inventory balance equation for the oxygen deficit. Equation (17) defines $E_{i}$, while equation (18) defines $F_{i}$. Constraints (19) and (20) are the water quality constraints; constraints (21) are treatment efficiency constraints. A more detailed discussion of this model is given in Revelle et al. (1968).

The empirical application for this research is based on the model structure shown above. A base case data given in Revelle et al. (1968) was used to derive a numerical solution for equations (13) - (21). The discharger 1 is assumed to treat its waste at $67 \%$ (Liebman and Lynn, 1966). The model structure is then extended to the constraint method of multi-objective programming model framework such as the one given by equations (22) - (24). This model is solved by four steps shown in Section 4 (see also Figure 3).

Set two objectives, maximizing the water quality and minimizing the treatment cost. Put the objective of minimizing the treatment cost in constraint. The other constraints [same as equations (14) - (21)] are from the least-cost model (Revelle et al. 1968). The following is the constraint method of multi-objective programming model in water quality management.

$$
\begin{gathered}
\text { Minimize } Z_{1}\left(X_{1}, X_{2}, \ldots, X_{n}\right) \\
\text { St. }\left(X_{1}, X_{2}, \ldots, X_{n}\right) \in F_{d} \\
Z_{2}\left(X_{1}, X_{2}, \ldots, X_{n}\right) \geq L_{2}
\end{gathered}
$$

where

$Z_{1}$ is water quality objective function, $Z_{1}=M_{1}+M_{2}+\ldots .+M_{11}$,

$M_{i}$ is the emission discharged by reach $i, i=1,2, \ldots . .11$,

$Z_{2}$ is the least treatment cost function, which is the same as equation (13),

$X_{n}$ is the decision variables, $n=1,2, \ldots, 11$,

$L_{2}$ is the lower bound of $Z_{2}$, which is set at the value from the solution of the least-cost model, from equation (13) to equation (21).

Equation (23) is assigned as these equations from equation (14) to equation (21). Then $L_{2}$ is increased incrementally until the solution becomes infeasible. When the problem is solved at every value of $L_{2}$, it yields a point in the non-inferior set. The point in the non-inferior set decides the total emission, the least treatment cost, and the tax revenue. That is because the level of the least treatment cost decides not only the set of tax rates (shown in Table 1)

\begin{tabular}{|c|c|c|c|c|c|c|c|c|c|}
\hline \multirow{3}{*}{ Tax } & \multirow[t]{3}{*}{ Discharger } & \multicolumn{8}{|c|}{ Points on the Transformation Curve } \\
\hline & & $\mathrm{A}$ & $\mathrm{B}$ & $\mathrm{C}$ & $\mathrm{D}$ & $\mathrm{E}$ & $\mathrm{F}$ & $\mathrm{G}$ & $\mathrm{H}$ \\
\hline & & & & & & & & & \\
\hline \multirow[t]{10}{*}{ Rate } & 2 & 0.001496 & 0.001496 & 0.001496 & 0.001496 & 0.001496 & 0.001496 & 0.001496 & 0.001496 \\
\hline & 3 & 0.000126 & 0.000126 & 0.000126 & 0.000126 & 0.000126 & 0.000126 & 0.004237 & 0.004237 \\
\hline & 4 & 0.003727 & 0.003727 & 0.003727 & 0.003727 & 0.003727 & 0.003727 & 0.003727 & 0.003727 \\
\hline & 5 & 0.000656 & 0.000656 & 0.000656 & 0.000656 & 0.000656 & 0.000656 & 0.000656 & 0.014046 \\
\hline & 6 & 0.000475 & 0.000475 & 0.000475 & 0.000475 & 0.000475 & 0.000475 & 0.000475 & 0.000475 \\
\hline & 7 & 0.006631 & 0.006631 & 0.006631 & 0.006631 & 0.006631 & 0.006631 & 0.006631 & 0.006631 \\
\hline & 8 & 0.000863 & 0.000863 & 0.000863 & 0.000863 & 0.000863 & 0.000863 & 0.000863 & 0.000863 \\
\hline & 9 & $3.02 \mathrm{E}-05$ & 0.000118 & 0.000118 & 0.000118 & 0.000118 & 0.000118 & 0.000118 & 0.000118 \\
\hline & 10 & $4.08 \mathrm{E}-06$ & $2.75 \mathrm{E}-05$ & $2.75 \mathrm{E}-05$ & $2.75 \mathrm{E}-05$ & $2.75 \mathrm{E}-05$ & $2.75 \mathrm{E}-05$ & $2.75 \mathrm{E}-05$ & $2.75 \mathrm{E}-05$ \\
\hline & 11 & 0.002889 & 0.002889 & 0.002889 & 0.002889 & 0.002889 & 0.002889 & 0.002889 & 0.002889 \\
\hline$\lambda_{\Lambda}$ & & & & & & & & & \\
\hline Revenue & & 1.630000 & 1.44659 & 1.34659 & 1.24659 & 0.94659 & 0.646588 & 0.533911 & 0.557692 \\
\hline
\end{tabular}
but also the emission (shown in Table 2) in each discharger.

Table 1. Tax revenue and tax rate corresponding to points on the transformation curve

Tax Rate and Revenue in Millions of Dollars 
Table 2. Emission corresponding to points on the transformation curve

\begin{tabular}{|c|c|c|c|c|c|c|c|c|c|}
\hline \multirow{3}{*}{ Emission } & \multicolumn{3}{|l|}{ Discharger } & \multicolumn{6}{|c|}{ Points on the Transformation Curve } \\
\hline & & A & B & $\mathrm{C}$ & $\mathrm{D}$ & $\mathrm{E}$ & $\mathrm{F}$ & G & $\mathrm{H}$ \\
\hline & 2 & 184.60 & 139.30 & 72.50 & 42.6 & 42.60 & 42.60 & 42.60 & 42.60 \\
\hline & 3 & 46.29 & 21.24 & 21.24 & 21.2 & 21.24 & 21.24 & 11.80 & 11.80 \\
\hline & 4 & 78.65 & 78.65 & 78.65 & 78.7 & 78.65 & 21.77 & 12.10 & 12.10 \\
\hline & 5 & 60.45 & 24.18 & 24.18 & 24.2 & 24.18 & 24.18 & 24.18 & 9.34 \\
\hline & 6 & 156.00 & 24.00 & 24.00 & 24.0 & 24.00 & 24.00 & 24.00 & 24.00 \\
\hline & 7 & 42.25 & 42.25 & 42.25 & 42.3 & 42.25 & 42.25 & 23.56 & 9.75 \\
\hline & 8 & 143.86 & 102.00 & 102.00 & 102.0 & 102.00 & 102.00 & 102.00 & 102.00 \\
\hline & 9 & 360.00 & 144.00 & 144.00 & 144.0 & 144.00 & 144.00 & 144.00 & 144.00 \\
\hline & 10 & 800.29 & 218.00 & 218.00 & 218.0 & 218.00 & 218.00 & 218.00 & 218.00 \\
\hline & 11 & 181.35 & 181.35 & 181.35 & 162.2 & 58.36 & 27.90 & 27.90 & 27.90 \\
\hline $\begin{array}{l}\text { Variable } \\
\text { Cost }\end{array}$ & atment & 1.08 & 1.30 & 1.40 & 1.5 & 1.80 & 2.1 & 2.30 & 2.60 \\
\hline Total Emi & ssion & 2,054 & 975 & 908 & 859 & 755 & 668 & 630 & 602 \\
\hline
\end{tabular}

\section{Solutions and Results}

The solution of the non-inferior set for point $\mathrm{A}$ to $\mathrm{H}$ is shown on Table 3, Figure 4, and Figure 5. For example, in order to get point $A$, the lower bound $\left(L_{2}\right)$ is set as $\$ 1.076$ million (the least treatment cost), which is solved from the least-cost model. This value is used to solve the problem in constrained method of a multi-objective programming model. It gets the total emission 2,054 mg/liter. At the same time, the level of the least treatment cost (\$1.076 million) also decides the set of tax rates and the set of emission of each discharger, which is shown in Tables 1 and 2. The relationship between the total least treatment cost and total emission is shown in Figure 4. The relationship between the water quality (negative total emission) and tax revenue is shown in Figure 5. Point A has total emissions of 2,054 $\mathrm{mg} /$ liter and total revenue of $\$ 1.63$ million. The relationship between the total least treatment cost and total emission has some degree of tradeoff relationship. The relationship between water quality (negative total emission) and total tax revenue can be found by connecting these points, from point A to point $\mathrm{H}$, shown in Figure 5. We found that they have a tradeoff relationship except with any point between $\mathrm{G}$ and $\mathrm{H}$ that has a positive relationship. After point $\mathrm{H}$, it is infeasible. Therefore, we stop at point $\mathrm{H}$.

Table 3. Total emission and tax revenue corresponding to points on the transformation curve

\begin{tabular}{lcccccccc}
\hline \hline & \multicolumn{7}{c}{ Points on the Transformation Curve } \\
\cline { 2 - 9 } & $\mathrm{A}$ & $\mathrm{B}$ & $\mathrm{C}$ & $\mathrm{D}$ & $\mathrm{E}$ & $\mathrm{F}$ & $\mathrm{G}$ & $\mathrm{H}$ \\
\cline { 2 - 9 } Total Emission & 2054 & 975 & 908 & 859 & 755 & 668 & 630 & 602 \\
Tax Revenue & 1.630 & 1.450 & 1.350 & 1.250 & 0.950 & 0.650 & 0.530 & 0.560 \\
Variable Treatment Cost & 1.076 & 1.300 & 1.400 & 1.500 & 1.800 & 2.100 & 2.300 & 2.600 \\
Total Treatment Cost & 2.968 & 3.192 & 3.292 & 3.392 & 3.692 & 3.992 & 4.192 & 4.492 \\
\hline \hline
\end{tabular}

Tax revenue and Treatment Cost is Millions of Dollars

Fix Treatment Cost $=1.892$

Emission is $\mathrm{mg} / \mathrm{liter}$

It is important to use the multi-objective programming in water quality management. For example, if we use the traditional single objective, the solution will be in point A (tax revenue objective only) or in point $\mathrm{H}$ (water quality objective only). The advantage of this model is using multi-objective programming to find the efficient set of 
solutions. Any points in the non-inferior set are efficient. These points offer the information for policy makers or decision makers to make a decision by political process or their favor.

In general, if we only have the optimal alternative without the preference information, the optimal point is hard to choose. Two approaches, the geometrical argument approach and the tradeoff analysis approach (Cohon and Marks, 1973, p.835), could be used to help a decision maker find an optimal point.

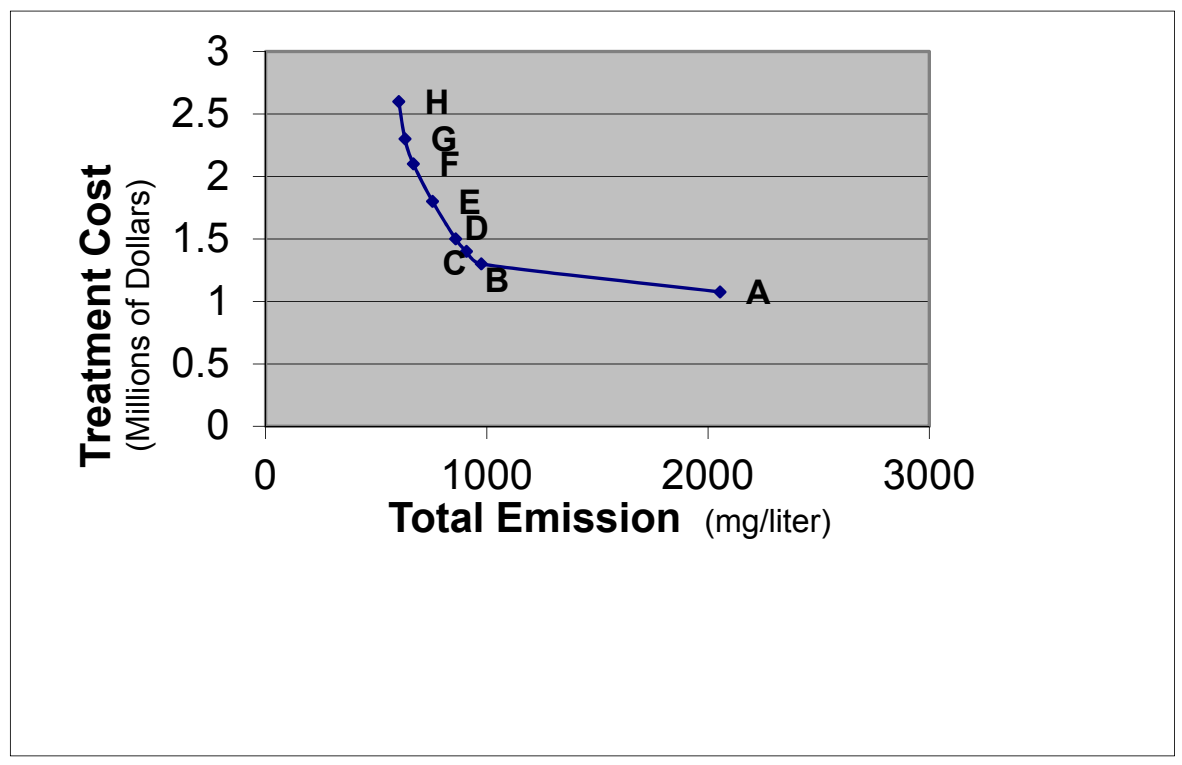

Figure 4. Trade-off betweentreatment cost and total emission

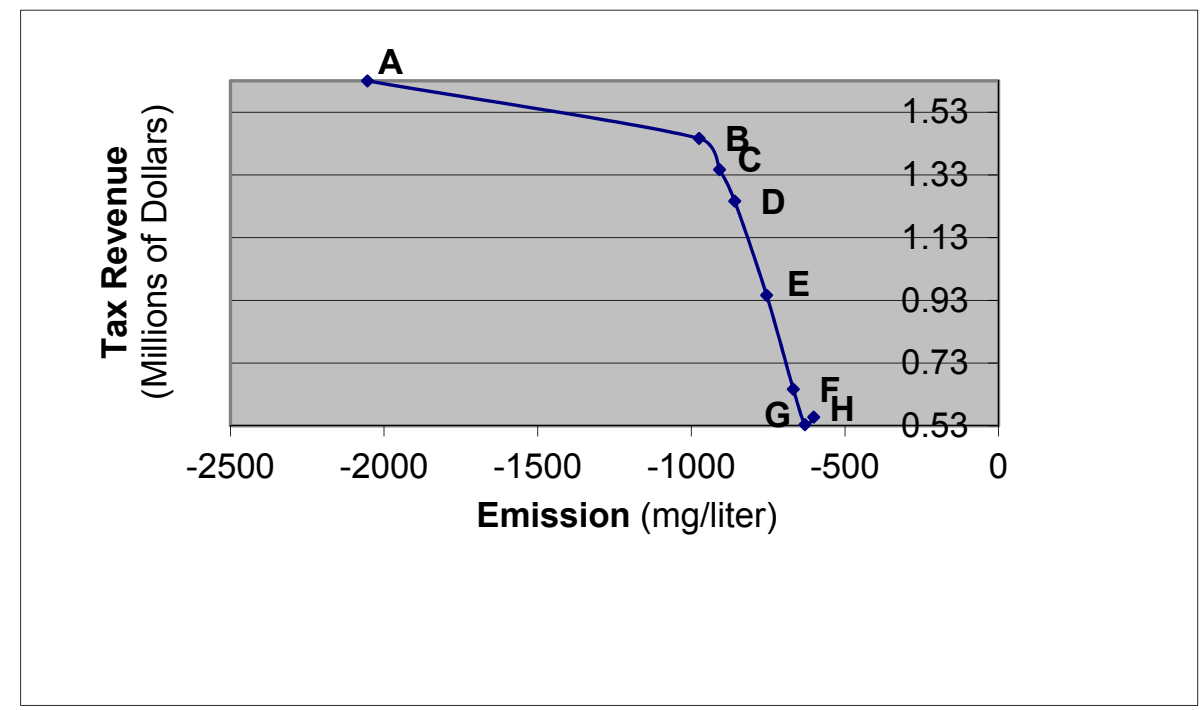

Figure 5. Transformation curve between tax revenue and water quality (emission)

In this case, the decision-making process may decide the optimal plan by the information that is given in Figure 5 and Table 1. We may expect the decision maker will choose point B by using a geometrical argument approach. That is because point B is very similar to the optimum for a typical IC (indifferent curve) in Figure 6. The tradeoff analysis approach is also a good method to decide the optimal point for a decision maker. In this case, the decision maker may not choose any points between point $\mathrm{A}$ and point $\mathrm{B}$ in Figure 5 because a relatively large amount of water quality is sacrificed in order to gain some tax revenue when moving from B to A. In the same theory, any points between point $\mathrm{B}$ and $\mathrm{H}$ are not a good choice because a relatively large amount of tax revenue is sacrificed in order 
to gain some water quality when moving from B to H. Therefore, point B is a good choice for the optimal point using both the geometrical argument approach and the trade off analysis approach.

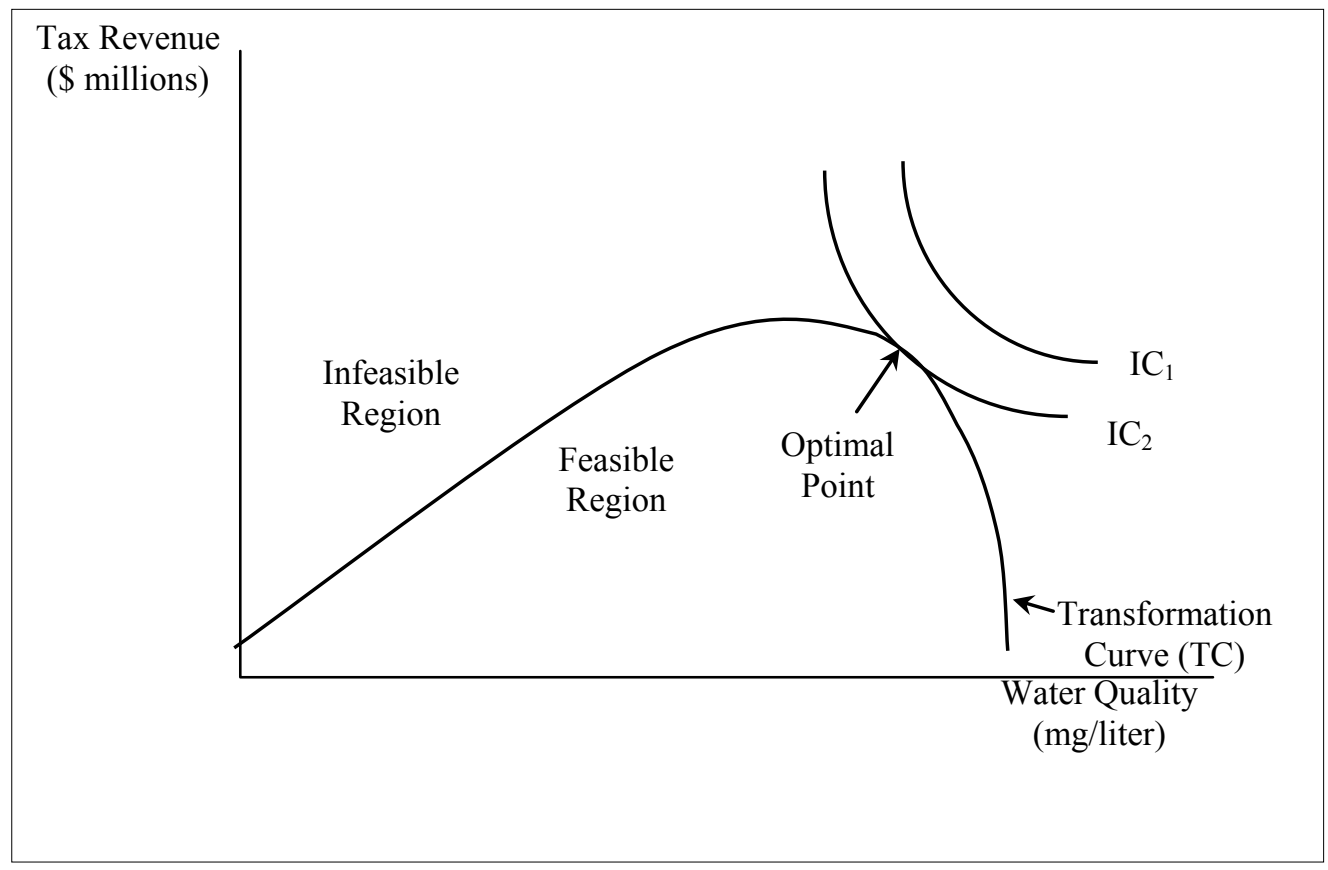

Figure 6. Multi-objective analysis by graph

\section{References}

Ballestero, E., \& C. Romero. (1998). Multiple Criteria Decision Making and Its Applications to Economic Problems. Boston: Kluwer Academic Publishers. https://doi.org/10.1007/978-1-4757-2827-9

Barde, J., \& S. Smith. (1997). Do Economic Instruments Help the Environment? The OECD Observer.

Barnett, B., Blake, B., \& McCarl, B. (1982). Goal Programming via Multidimensional Scaling Applied to Senegalese Subsistence Farms. American Journal of Agricultural Economics, 64, 720-727. https://doi.org/10.2307/1240581

Baumol, W.J., \& Oates, W.E. (1988). The Theory of Environmental Policy (2nd ed.). Cambridge MA: Cambridge University Press. https://doi.org/10.1017/CBO9781139173513

Brill, E.D. (1997). Effluent Charges and Transferable Discharge Permits. In C. Revelle and A. McGarity (Eds.), Design and Operation of Civil and Environmental Engineering Systems (p. 672). New York. John Wiley \& Sons.

Brill, E.D., Jr. (1979). The Use of Optimization Model in Public-Sector Planning. Management Science, 25, 413-422. https://doi.org/10.1287/mnsc.25.5.413

Burke, M. (1997). Environmental Taxes Gaining Ground in Europe. Environmental Science \& Technology/News, 31(2), 84-88. https://doi.org/10.1021/es9721273

Chrisman, J.J., Fry, T., Reeves, G.R., Lewis, H.S., \& Weinstein, R. (1989). A Multiobjective Linear Programming Methodology for Public Sector Tax Planning. Interfaces, 19, 13-22. https://doi.org/10.1287/inte.19.5.13

Cohon, J.L. (1978). Multi-objective Programming and Planning. New York: Academic Press. 
Cohon, J.L., \& Marks, D.H. (1973). Multi-objective Screening Models and Water Resources Investment. Water Resources Research, 9(4), 826-836. https://doi.org/10.1029/WR009i004p00826

Deb, K. (2014). Multi-objective optimization. In Search methodologies (pp. 403-449). Springer US. https://doi.org/10.1007/978-1-4614-6940-7_15

Liebman, J.C., \& Lynn, W.R. (1966). The Optimal Allocation of Stream Dissolved Oxygen. Water Resources Research, 2, 581-591. https://doi.org/10.1029/WR002i003p00581

Loucks, D.P., Revelle, C.S., \& Lynn, W.R. (1967). Linear Programming Models for Water Pollution Control. Management Science, 14, B166-B181. https://doi.org/10.1287/mnsc.14.4.B166

Metcalf, G.E. (2009). Designing a Carbon Tax to Reduce Greenhouse Gas Emissions. Review of Environmental Economics and Policy, 3, 63-83. https://doi.org/10.1093/reep/ren015

Oates, W.E. (1993). Pollution Charges as a Source of Public Revenues. In H. Giersch (Ed.), Progress and Environmental Concerns (pp. 135-152). Berlin: Springer-Verlag. https://doi.org/10.1007/978-3-642-78074-5_6

Oates, W.E. (1995). Green Taxes: Can We Protect the Environment and Improve the Tax System at the Same Time?. Southern Economic Journal, 61, 915-922. https://doi.org/10.2307/1060731

Revelle, C.A., Loucks, D.P., \& Lynn, W.R. (1968). Linear Programming Applied to Water Quality Management. Water Resources Research, 4, 1-9. https://doi.org/10.1029/WR004i001p00001

Romero, C., \& Rehman, T. (2003). Multicriteria Analysis for Agricultural Decisions (2nd ed.). Amsterdam: Elsevier.

Roskamp, K.W. (1972). Multiple Fiscal Policy Objectives and Optimal Budget: A Programming Approach. Public Finance, 26, 361-378.

Spronk, J., \& Veeneklaas, F. (1983). A Feasibility Study of Economic and Environmental Scenarios by Means of Interactive Multiple Goal Programming. Regional Science and Urban Economics, 13, 141-160. https://doi.org/10.1016/0166-0462(83)90009-1

Tietenberg, T. (1985). Emissions Trading: An Exercise in Reforming Pollution Policy. Washington, D.C.: Resources for the Future.

Wen, Ching-Gung, \& Lee, Chih-Sheng. (1998). A Neural Network Approach to Multi-objective Optimization for Water Quality Management in a River Basin. Water Resources Research, 34(3), 427-436. https://doi.org/10.1029/97WR02943

Wheeler, B.M., \&Russell, J.R.N. (1977). Goal Programming and Agricultural Programming. Operations Research Quarterly, 28, 21-32. https://doi.org/10.1057/jors.1977.2 